PREM KUMAR, in a view from Alberta, writes

\section{In defence of Canada Land Inventory}

The Canada Land Inventory is regarded as both a blessing and a bane. It could provide a ready reference or cause a mental block. It is a time saver or can make you highly prejudicial. It is astonishing how with all the available information on soils, climate, geomorphology, and the renewable resources, etc. it could still be significantly off the mark. But such cases are infrequent and wherever present are indicative of a faulty judgement, not a spurious system. Overall, despite spotty disappointment, $\mathrm{CLI}$ is good to have in a large country like ours.

\section{What it provides}

The CLI gives information suited for broad planning and for intensive management. For broad planning it indicates the general character of the land resource with regard to its requisite uses, say, agriculture, forestry, wildlife, and recreation. It locates and evaluates their physical worth. This evaluation is a ranking system of potentialities or capabilities. The ranking system is based upon a firm and comprehensive criterion relative to each use. And this is the way it should be, because each use is singular in its characteristics. It is the appreciation and detection of this criterion that ensures assignment of the correct capability class along with the characteristics present at one given time. However, it is a lack of appreciation and/or detection of such criterion that causes all the argument about faulty assignment of capability ratings. It is not far fetched to compare capability to personality and capability limitations to personality traits.

Despite claims to the contrary, $\mathrm{CLI}$ also helps to make wise decisions regarding individual parcels of land. And why not? The $\mathrm{CLI}$ gives the rating classes. The rating class is a measure of the quality of land for a specific use. The rating classes cover the entire gamut of resource conditions that could exist - from the most suitable to the most unsuitable. The management implications for each class, therefore, become more than apparent.

Thus CLI classes for agriculture locate lands that are suitable specifically for the production of annual field crops, forage, improved pasture and native grazing. Likewise, forestry capability classes show extent of lands capable of producing given quantities of wood. This wood production is the measure of land quality. Management decisions are, therefore, possible regarding lands that should be set aside for forestry. A comprehensive array of capability classes for recreation and wildlife also helps to make wise management decisions relative to these uses.

As an additional guide to management, $\mathrm{CLI}$ provides information regarding limitations present in a given area. In fact, limitations form an integral part of the rating system. Limitations are actually physical handicaps because of climatic, surface and subsurface conditions that restrict optimal use and/or production of resources. The $\mathrm{CLI}$ has done a thorough job of enumerating all possible limitations that could be present at any given time. There are, for instance, thirteen limitations listed for agriculture alone, and nineteen for forestry. In short, the capability class gives the general quality of a given piece of land, while limitations provide clues as to development or management constraints.

Objections are raised sometimes that capability maps are not at a large enough scale to depict all limitations extant, however small. This, it is argued, restricts blanket use of CLI for management, but is a poor argument. No land inventory could indicate all limitations (significant and insignificant) on a map and still be a practical reference. Such a map would invariably be cluttered and a manager likely to be more confused than enlightened. Besides, a good land manager knows his land well. He will not be oblivious to shortcomings of an individual parcel of land, say, the presence of a 'few wet spots', or 'a steep marginal ridge.' To these pieces he would of course give differential and appropriate treatment for land-culture. Nevertheless, the CLI gives him an overview of quality of land and limitations present. Those who have prepared land use plans know by experience that a land manager is an uncanny judge of what he is dealing with. Experience therefore supports the view that $\mathrm{CLI}$ is a reliable guide to management.

On a purely philosophical plane, it is not invalid to suggest that no two parcels of land are alike as their mere difference in location in the landscape makes them 'different.' This is an extension of the philosophical argument which deems each individual different and unique. But such an argument if applied to natural resources will demolish all classification systems (soils, zoological, botanical, etc). Philosophically, then, $\mathrm{CLI}$ is a reasonable system.

\section{Sources of confusion and clarity}

1/ The soil capability classes. The capability classes are generally accurate as assignment is based on an association of soil series, the dominant series along with topographical features generally determining the class. However, confusion arises when a land unit contains minor pockets of lower quality soils. These pockets were of course ignored on maps of 1: 250,000 scale. At the management level these pockets have to be delineated and rated separately. This is not the shortcoming of the system, but of the map scale. 2/ The capability classes for forestry. This rating procedure is ostensibly sound as it is based in part on one quantifiable criterion, that is, productivity in cubic feet of the indicator species, such as white spruce. The problem arises as stocking and normality are lacking in most forests. In such cases occular estimation in the field or with aerial photographs can be significantly faulty. Also, all areas under cultivation lack a forest cover. Forestry ratings of these areas will 
be difficult. Present forest cover does not determine the capability ratings. Rather it is the sum total of many ecological and biological factors. Nevertheless, the forest cover on a given soil will undoubtedly be a sure guide to its quality. It is not uncommon to find that many unforested and cultivated areas have been instinctively rated for forestry. Fortunately, field experience has shown that ratings have largely been accurate. The reliability of $\mathrm{CLI}$ is proven here too.

3/ The capability classes for wildlife. I have not been able to divine reasons for blanket assignment of one single rating for ungulates across the board over vast tracts comprised of diverse characteristics such as topography, soils, and interspersion of muskegs. For instance, capability class 4 seems to be a favourite in Alberta, straddling diverse areas. Presumably this could be explained if one examines a few contiguous townships of one type of physiography at a time. In such a situation interspersion of small muskegs forms an integral part of the landscape and wildlife (moose, elk, deer) would equally prefer muskegs along with mineral soil as their normal habitat conducive to protection and food. The assumption here is that a variegated ecosystem is desirable, hence one capability rating is plausible. However, this logic is inadmissible when miles and miles of contiguous muskegs are given a rating equal to the habitat described above. Perhaps this is a weakness of the CLI. The ecology of moose, elk, and deer is relatively simple and well documented. The modification of the CLI ratings does not present insurmountable problems.

As in the above case, capability ratings for waterfowl are placed with a broad sweep. It is not uncommon to find very large areas (15 to 20 townships) allotted a rating of 6 . Again, modifications are warranted and easily done.

4/ The capability classes for outdoor recreation. The capability classes seem to have been aptly applied. However, there is a surfeit of subclasses $E, O, P$, and $Q$ in the CLI maps of Alberta. This routine and casual use of these subclasses is questionable.

Location and present access do not determine the capability class, so it is laid down. Yet a recreation resource located near to a metropolitan area and inten- sively used seems to have received higher ratings. No doubt this resource sustains and generates 'use', but 'use' is not because of its superior endowment, but because of the paucity of an alternate resource. Perhaps the situation is analagous to that of a man placed in isolation in Northern Canada to whom a week-old newspaper could provide all the interest and excitement which a fresh paper provides to a city dweller.

\section{Conclusions}

The CLI ratings have proved not only the starting point for understanding of our vast natural resources, but also the system has converged thinking on evaluation of resources. Already we have in a few years passed the threshold of an awareness stage. In fact the adoption stage has also been crossed and we are in the midst of an evaluation stage. New refinements will come with time, but it appears the foundations have been worthily laid. Canada is one of the few countries in the world which is looking at its resources and their planning in an enlightened manner. To this end CLI has been a potent element.

\section{Land Use}

Oft on a swivel-chair he reclines,

Grey-streaked and pensive demeanour,

And a distant look in his eyes.

$A$ relapse into a reverie or

A ploy to waste government time?

There are low sighs,

And half-crushed whines,

And then a mark of exclamation

"This is great, this is fine."

Doggedly he probes

low, high and on sides -

this feature, that physiognomy, those slopes,

that lush growth, hummocks deep and wide!

Pursue he must the sinuous trails,

And expertly surmise all body marks.

Haltingly he fathoms the crooked breaks.

There she lies - silent, serene and stark!

Who is he, who is she?

Pray, someone spake.

Well, he is a photo-interpreter,

And she is a landscape.

Both of them on aptly combining

Are technically called Biophysical Planning.

Prem Kumar 